\title{
Autologous EBV-CTL CD19CAR zeta
}

National Cancer Institute

\section{Source}

National Cancer Institute. Autologous EBV-CTL CD19CAR zeta. NCI Thesaurus. Code C78824.

Autologous Epstein-Barr virus (EBV)-specific cytotoxic T-lymphocytes (CTL) that have been genetically modified to express a T-cell chimeric antigen receptor (CAR) targ eting the CD19 antigen, with potential immunotherapeutic activity. The CAR consists of a single chain Fv of anti-CD19 IgG1 coupled with an intracellular signaling region of the zeta-chain of the TCR/CD3 complex (CD3 zeta). Autologous EBV-CTL CD19CAR zeta directs the Tlymphocytes to CD19-expressing tumor cells, stimulating a selective toxicity to tumor cells. CD19 antigen is a B-cell specific cell surface antigen expressed in all B-cell lineage malignancies. 